\title{
Notched Strength of Woven Fabric Kenaf Composites with Different Fiber Orientations
}

\author{
Hilton Ahmad ${ }^{1, *}$, and Safwan Rahim ${ }^{1}$ \\ ${ }^{1}$ Faculty of Civil and Environmental Engineering, Universiti Tun Hussein Onn Malaysia, 86400 Parit \\ Raja, Batu Pahat, Johor, Malaysia.
}

\begin{abstract}
The awareness of implementing sustainable materials in construction industry is gaining good attention among engineers worldwide. Kenaf fibers are local renewable materials to combine with epoxy polymers matrix in producing lightweight composite materials which may replace imported synthetic fiber composites especially in developing countries. Other benefits of using kenaf fiber composites are relatively cheap, less abrasive and less hazardous during fabrication handling. Current study investigates parametric study on notched strength of woven fabric kenaf composite plates with different fiber orientations and circular hole sizes. Stress concentration occurred at the notch edge promotes to micro-damage events such as matrix cracking and fiber fracture as remote tensile loading applied. Current study showed that $0^{\circ}$ fiber orientation gives optimum notched strength, plates with larger fiber tilting than $0^{\circ}$ are associated with further strength reduction. Kenaf fibers give an alternative to material designers to opt woven fabric kenaf composites in low and medium load bearing applications.
\end{abstract}

\section{Introduction}

Materials engineers and scientists had started to use natural fibres in composite materials fabrications due to comparable specific strength (and stiffness) to synthetic fibre composites (e.g. GFRP). Kenaf fibre has excellent strength and modulus properties [1], thus potentially used as fibre reinforcement in composite system. Large amount of research works were reported to improve the mechanical properties of this materials (such as adding composite fillers) to demonstrate the applicability of kenaf composites system as an advanced engineering materials [1-2]. The drawback of hydrophilic nature of kenaf fibres may provide poor adhesion with polymer, but less significant effect were exhibited when combined with thermo-set polymer than thermoplastic polymer counterparts [2].

Woven fabric fibre composites are another class of reinforcing fibre system in composite materials. It has lower strength than unidirectional fibre composites due to existence of crimping region. However, woven fabric composite system has good drapeability for manufacturing processes, superior resistance against fatigue and impact loading. However, due to large arrays of woven fabric composite combinations (lay-up types,

* Corresponding author: hilton@uthm.edu.my 
weaving architectures, fiber orientations, etc.), different failure mechanisms may exhibit in different fibre reinforcing/binders combination systems.

Most structures assembly are joined by bolted joints, which requires introduction of notch in composite plates. It is important to study the behaviour of the notch plate prior to implementation of composite materials in bolted joints system. Due to discontinuity of plate geometry, stress raisers are exhibited at the vicinity of the notch edge. The critical length from the notch edge showed complex damage mechanisms, comprised of matrix cracking, splitting, delamination and ultimately $0^{\circ}$ fibre fracture. The critical length is associated with stable self-similar fashion damage prior to catastrophic failures along net-tension plane, and widely used as strength predictive parameter in notched composite plates [3-7]. Experimental works on woven fabric GFRP and CFRP system is slightly different in terms of critical length exhibited in both systems, however, it is suggested that the failure mechanisms showed similar damage fashion throughout all layers in a composite plate. This work can be further expanded to study structures response subjected to other stress raisers such as welded joints [8] and floor connections [9].

The behaviour of natural fibres composite system with notched plate is relatively very few as compared to synthetic fibre composites, and effect of fibre orientations on notched strength is remains vague. Current project aim to study effect of fiber orientations and hole size in woven fabric kenaf composite plates in more precise manner.

\section{Experimental frameworks}

Kenaf fiber yarns used in current project are processed fibers through drying stage, fiber grading stage (to conform uniformity) and formation of fiber yarn or string (by fibre twisting). Kenaf fiber threads available are in various diameter sizes, ranging between 0.75 $\mathrm{mm}$ to $3 \mathrm{~mm}$ diameter size. Current experimental work used kenaf fiber yarn with a diameter size of $0.75 \mathrm{~mm}$, weaved using handloom with extra precision. Extra care should be taken during hand lay-up weaving process as kenaf thread are sometimes easy to break apart (due to non-uniformity of kenaf yarn during yarn formation stage) to in-plane layer size of $250 \mathrm{~mm} \times 250 \mathrm{~mm}$.

Composite material strength is attributed to fiber-matrix adhesion. The poor adhesion can be avoided if the natural fibers are pre-treated beforehand prior to composite fabrications. However, it was reported that hydrophilic nature in kenaf composites is negligible by combining with thermoset polymers (e.g. epoxy resin). Current work use epoxy resin as matrix binder in composite fabrication stage. Amount of woven fabric kenaf layers and matrix binders (i.e., epoxy resin and hardener) are calculated based on materials weight.

Table 1. Testing series investigated in current work.

\begin{tabular}{|c|c|c|c|c|c|c|}
\hline \multirow[t]{2}{*}{$\begin{array}{l}\text { Weave } \\
\text { type }\end{array}$} & \multirow[t]{2}{*}{ Lay-up } & \multirow[t]{2}{*}{ Designation } & \multirow[t]{2}{*}{$\begin{array}{c}\text { Estimation } \\
\text { thickness (mm) }\end{array}$} & \multicolumn{3}{|c|}{$\begin{array}{l}\text { No. of testing coupons } \\
\text { (hole size) }\end{array}$} \\
\hline & & & & $2.5 \mathrm{~mm}$ & $5 \mathrm{~mm}$ & $10 \mathrm{~mm}$ \\
\hline \multirow{4}{*}{$\begin{array}{c}\text { Plain } \\
\text { weave } \\
(\mathrm{PW})\end{array}$} & $0^{\circ}$ & X0 & 0.7 & 3 & 3 & 3 \\
\hline & $15^{\circ}$ & $\mathrm{X} 15$ & 0.7 & 3 & 3 & 3 \\
\hline & $30^{\circ}$ & X30 & 0.7 & 3 & 3 & 3 \\
\hline & $45^{\circ}$ & X45 & 0.7 & 3 & 3 & 3 \\
\hline
\end{tabular}

The testing series involves various fibre orientations and notch sizes, three testing coupons are prepared for each testing series and notch sizes respectively as shown in Table 1. Material preparations and composite fabrication works were carried out in Textiles 
gauge length and plate width of $25 \mathrm{~mm}$ with notch sizes (i.e., hole diameters), $d$, of $2.5 \mathrm{~mm}$, $5.0 \mathrm{~mm}$, and $10.0 \mathrm{~mm}$ giving $d / W$ ratios of $0.1,0.2$ and 0.4 respectively. End tab is prepared for surface treatment to get good adhesion with aluminium strip to provide better gripping and to avoid testing coupon slippage during mechanical testing.

\section{Results and discussions}

Notched strength of testing coupons are calculated by using notched stress at failure expression by dividing peak load, $P_{\max }$ with its cross-section (i.e., a product of plate thickness, t and plate width, $W$ ) or can be mathematically expressed as, $\sigma_{N}=P_{\max } / W t$. There are four testing series as stipulated in Table 1 of different plate orientations and hole sizes. A number of orthogonal tows crossing over are given as " $n_{g}$ " which larger " $\mathrm{n}_{\mathrm{g}}$ " demonstrates higher degree of drapeability that is easier to form into complex shapes but reduced stability during manufacturing. However smaller " $n_{g}$ " improves impact resistance and tighter nesting for energy absorption. Current work used plain weave system $\left(n_{g}=2\right)$ and due to more crimping region, these fabric system may exhibited less strength as compared to other fabric systems with less crimping region such as harness satin $\left(n_{g}=8\right)$ or twill satin $\left(n_{g}=3\right)$. However, this fabric system is favorable due its stability during weaving process.

The failure modes of all testing coupons subjected to remote tensile testing was netsection failures associated with stress concentration. Net-section failure occurred at nettension plane, where cracks were initiated and propagated along net-tension plane. It was observed that crack was initiated at hole edge perpendicularly to applied load and progressively propagated to plate edge. Damage associated within damage zone comprised of not only limited to matrix cracking and splitting, but also fiber tow fracture. From Fig. 1, initially the notched plate of woven fabric kenaf composite displayed a linear elastic behavior until sudden fracture and brittle failure type were demonstrated. It is assumed that plastic deformation in tensile testing of notched plate is negligible, as found in other composite system (Belmonte [4, 5] and Manger [6]). Experimental observation found that a screeching sound can be heard after few minutes of testing machine started, associated with matrix cracking and fiber-matrix breakage occurred at notch edge. Thereafter, fiber fracture was taken place to indicate the reaching of peak load prior to catastrophic failures.

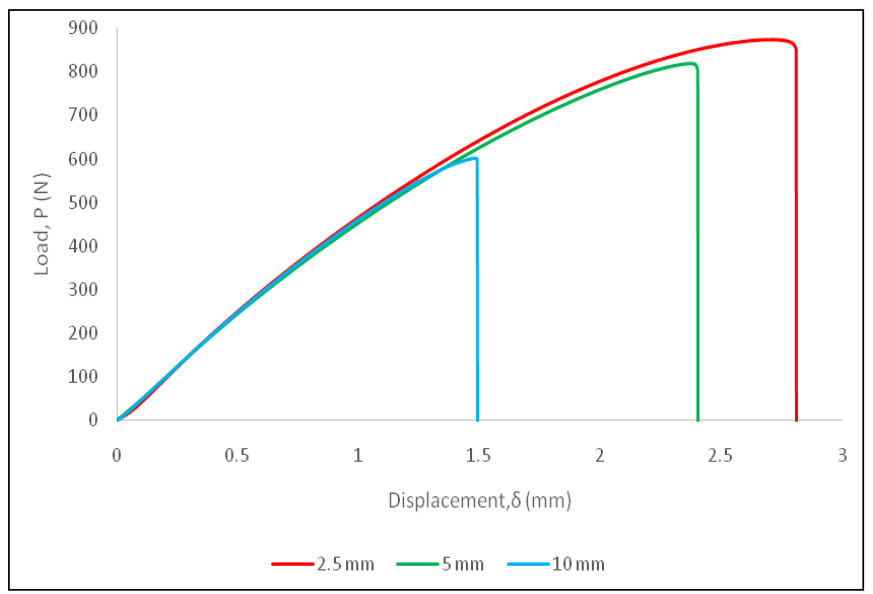

Fig. 1. Graph Load against Displacement of $0^{\circ}$ orientation notch for $2.5,5$ and $10 \mathrm{~mm}$ notch size. 
As remote tensile load is applied at the plate edge, crack initiation was created at netsection plane perpendicular to the applied remote loading. As the crack size reaching a critical length (associated with process zone length), catastrophic failure occured along nettension plane. At the process zone length, three types of micro damage events are expected to occur, i.e matrix cracking, delamination and fiber fracture at the vicinity of the hole edge. The size of damage zone length is approximately a size of hole radius as reported by previous researchers (Belmonte [4, 5] and Manger [6]). The notched strength decreased as hole size increased due larger remaining unloaded plate width also associated with smaller area of damage zone length developed at the hole vicinity prior to catastrophic failures as reported by Belmonte [5].

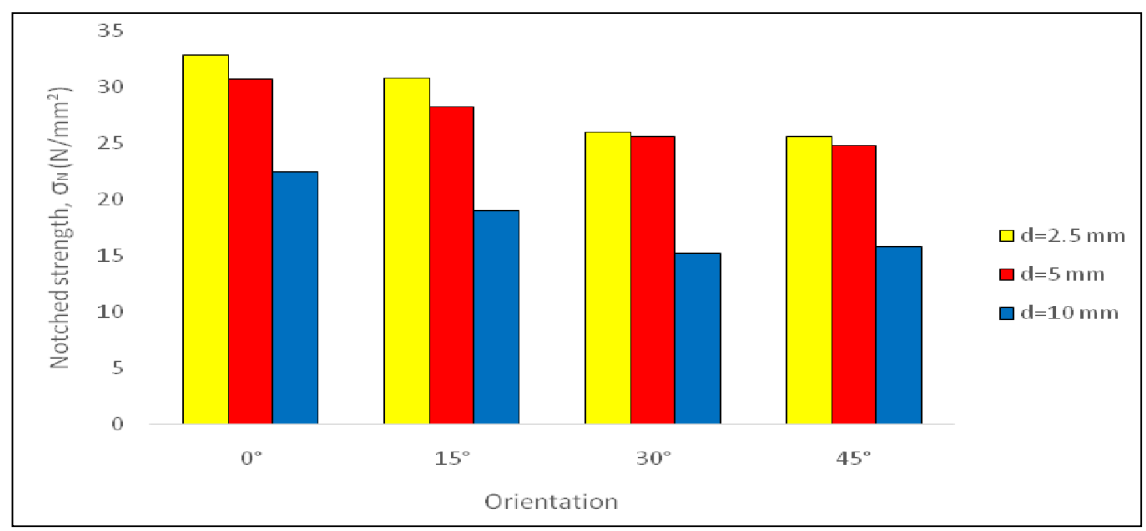

Fig. 2. Graph of notched stress at failures of various fibre orientations

Fig. 2 shows notched strength of all testing series with different fibre orientations. As expected, increased notched strength were observed with testing coupon of fiber orientation close to $0^{\circ}$ remote loading direction. On the other hand, decreased notched strength was seen in coupons with fiber orientation tilting further from $0^{\circ}$ fibre direction. Notice that the highest notched strength were given with coupon X0 with circular hole size of $2.5 \mathrm{~mm}$ to give notched stress at failure about $33 \mathrm{~N} / \mathrm{mm}^{2}$ and decreased accordingly as fiber orientation gets more inclination from $0^{\circ}$ fiber orientation. These trend is shown in fiber orientation of $15^{\circ}, 30^{\circ}$ and $45^{\circ}$ to give $30.84 \mathrm{~N} / \mathrm{mm}^{2}, 26 \mathrm{~N} / \mathrm{mm}^{2}$, and $25.64 \mathrm{~N} / \mathrm{mm}^{2}$ respectively. Similar trends were demonstrated to the other hole sizes. This is expected as fiber orientations are tilting further than remote applied loading direction, effective fiber direction to withstand ultimate loading capacity is further decreased. Bear in mind that a woven composite layer is equivalent to two layers of unidirection plies, therefore $0^{\circ}$ woven fabric layers has an orientation of (0/90) ply.

The effect of hole sizes to notched strength were also been carried out. All testing composite coupons was drilled using high speed drilling jig to produce a circular hole of different hole size (i.e., $2.5 \mathrm{~mm}, 5 \mathrm{~mm}$, and $10 \mathrm{~mm}$ ) for each fiber orientations plates understudied. The largest value of maximum load, $P_{\max }$ was given by $2.5 \mathrm{~mm}$ hole size coupons followed by $5 \mathrm{~mm}$ and $10 \mathrm{~mm}$ hole size respectively. The strength of $0^{\circ}$ fibre orientation is given as $32.9 \mathrm{~N} / \mathrm{mm}^{2}$ for $2.5 \mathrm{~mm}$ circular hole size followed by $30.7 \mathrm{~N} / \mathrm{mm}^{2}$ in $5 \mathrm{~mm}$ hole diameter and $22.51 \mathrm{~N} / \mathrm{mm}^{2}$ in $10 \mathrm{~mm}$ hole diameter. Increased notched strength in smaller hole size testing coupons are expected due to larger unloaded region from the vicinity of the notch as fracture energy (or strain energy) released is exceeded. It is also associated with the formation of damage zone length which formed perpendicularly to 
damage formation at the hole vicinity can help to explain lower strength of testing coupons with larger hole sizes. Belmonte (2004) conducted interrupted test (at $90 \%$ of peak load) to confirm the occurrence of matrix cracking, delamination and numbers of tow fracture under scanning electron microscope (SEM) investigations. However, interrupted test and determination of damage zone length is outside the scope of the current work.

\section{Conclusions}

Experimental observations showed that crack initiation was taken place at the vicinity of the hole edge and propagated to the plate edge along net-tension plane. The micro-damage formations are localized within damage zone length adjacent to the notch edge as results of matrix cracking, delamination and fiber fracture. It was found that $0^{\circ}$ fibre orientation and smaller hole size give optimum notched strength. $0^{\circ}$ fibre orientation is the direction of remote applied loading, therefore these direction is effective to resist applied load. Notched strength decreased gradually with larger hole size due to larger unloaded region width prior to catastrophic failures.

The author would like to thank Universiti Tun Hussein Onn Malaysia (Vot U245) to support this project work.

\section{References}

1. H.M. Akil, M.F. Omar, A. Mazuki, S. Safiee, Z. Ishak, A. Abu Bakar, Mater. Des., 32 (2011)

2. O. Faruk, A.K. Bledzki, H.P. Fink, M. Sain, Prog. Polym. Sci., 37 (2012)

3. H. Ahmad, A.D. Crocombe, P.A. Smith, Adv. Mat. Res., 845 (2014)

4. H.M.S. Belmonte, C.I.C. Manger, S.L. Ogin, P.A. Smith, R. Lewin, Comp. Sci. Tech., $61(2001)$

5. H.M.S. Belmonte, S.L. Ogin, P.A. Smith, R. Lewin, Comp. Pt. A, 35 (2004)

6. C.I.C. Manger, Failure of Notched Woven GFRP Composites: Damage Analysis and Strength Modelling. PhD Thesis, (Uni. of Surrey, 1999)

7. H. Ahmad, A.D. Crocombe, P.A. Smith, Plas. Rub. Comp., 42(3), (2013)

8. N. Abd Rahman, W. Tizani, Adv. Mat. Res. 1025, (2014)

9. N. Abd Rahman, Z. Jaini, N.A. Abd Rahim, S.A. Razak, InCEIC2014 (2014) 